METAgraphias: letra D de dropbox (das derivas dançantes) v.2 n.1 marçol2017 corpo contra conceito • Maria Eugênia Matricardi (m.eugeniamatricardi@gmail.com(




METAgraphias: letra D de dropbox (das derivas dançantes) v.2 n.1 marçol2017 corpo contra conceito • Maria Eugênia Matricardi (m.eugeniamatricardi@gmail.com(

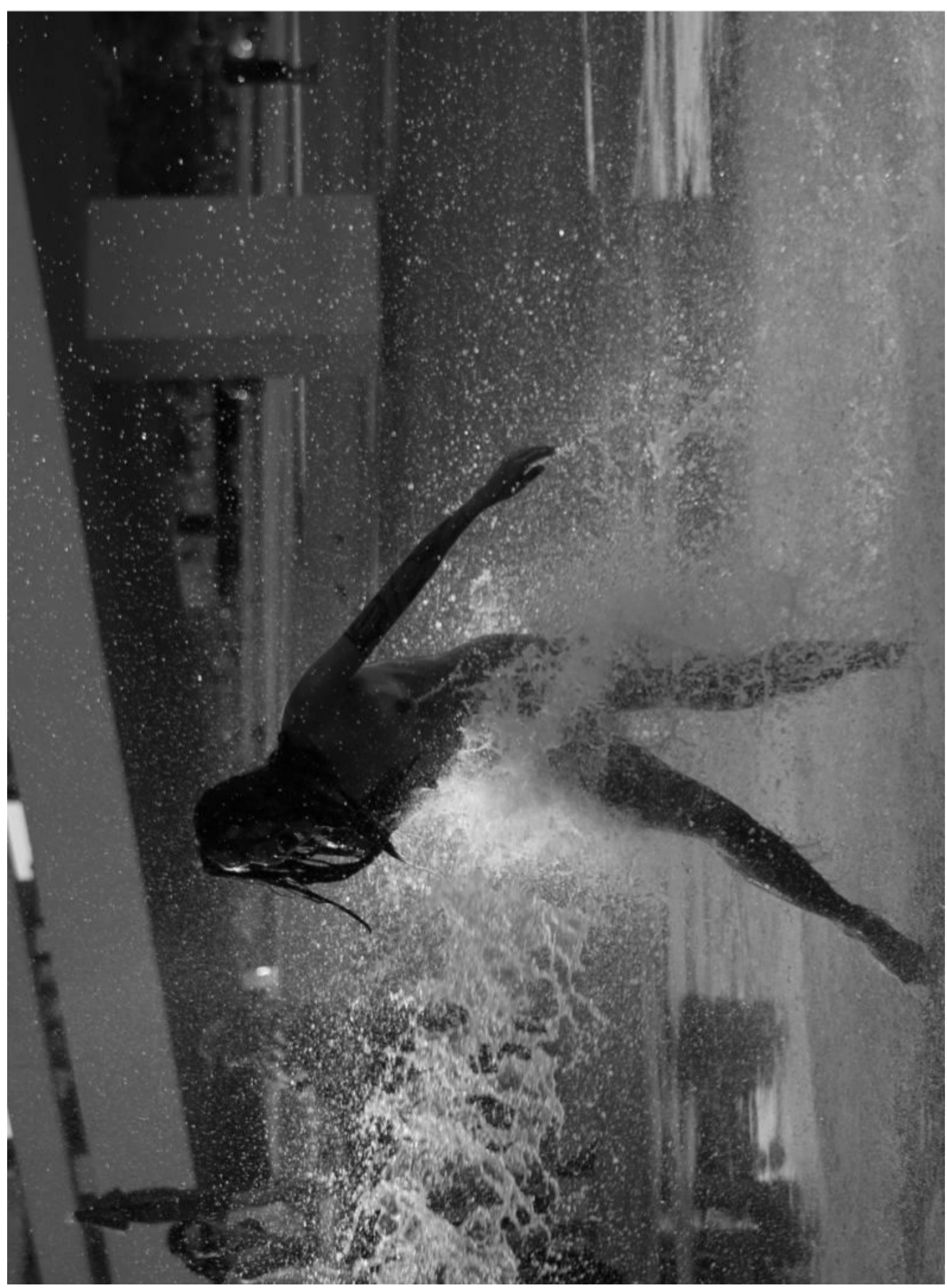




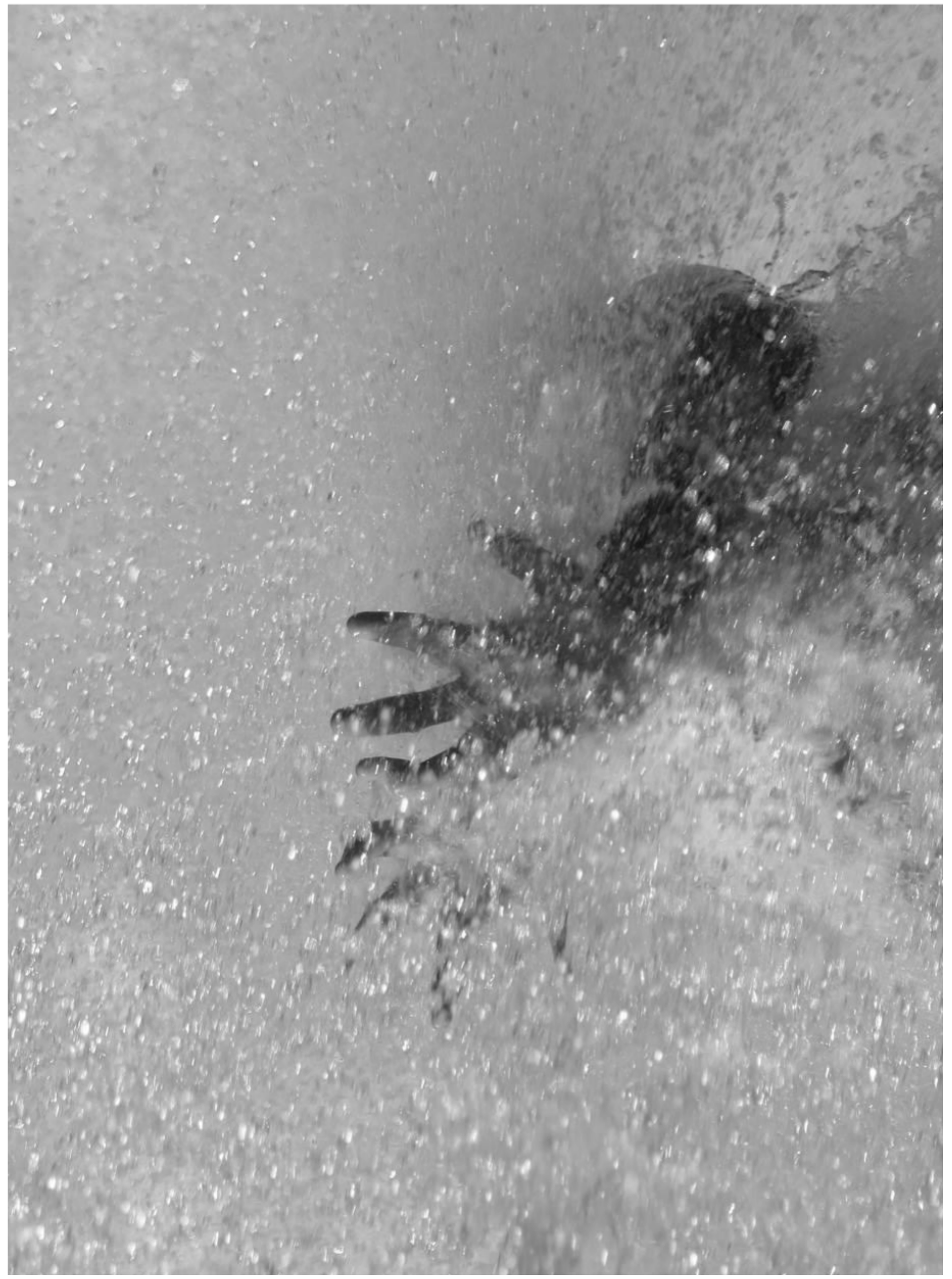


METAgraphias: letra D de dropbox (das derivas dançantes) v.2 n.1 marçol2017 corpo contra conceito • Maria Eugênia Matricardi (m.eugeniamatricardi@gmail.com(

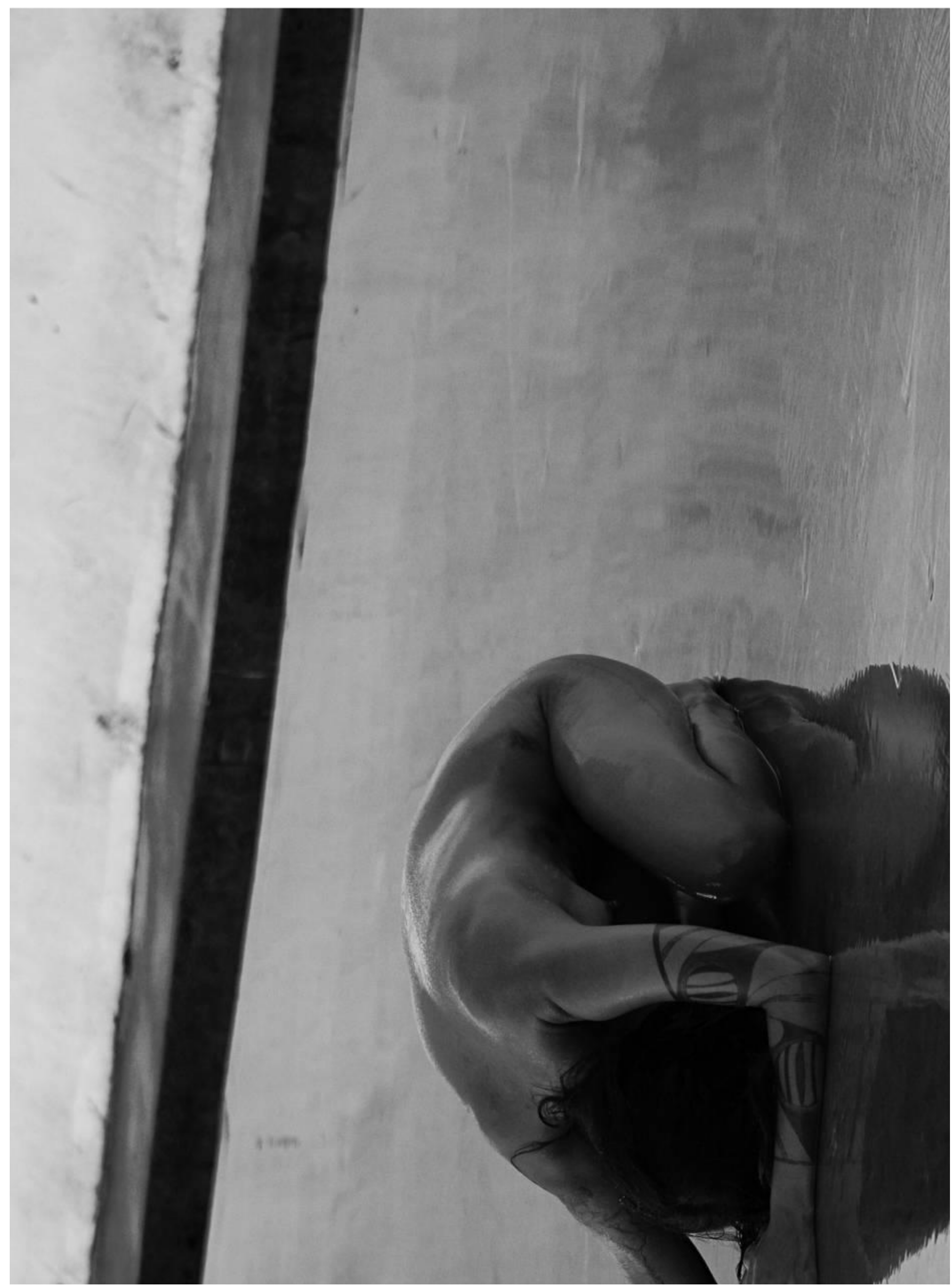




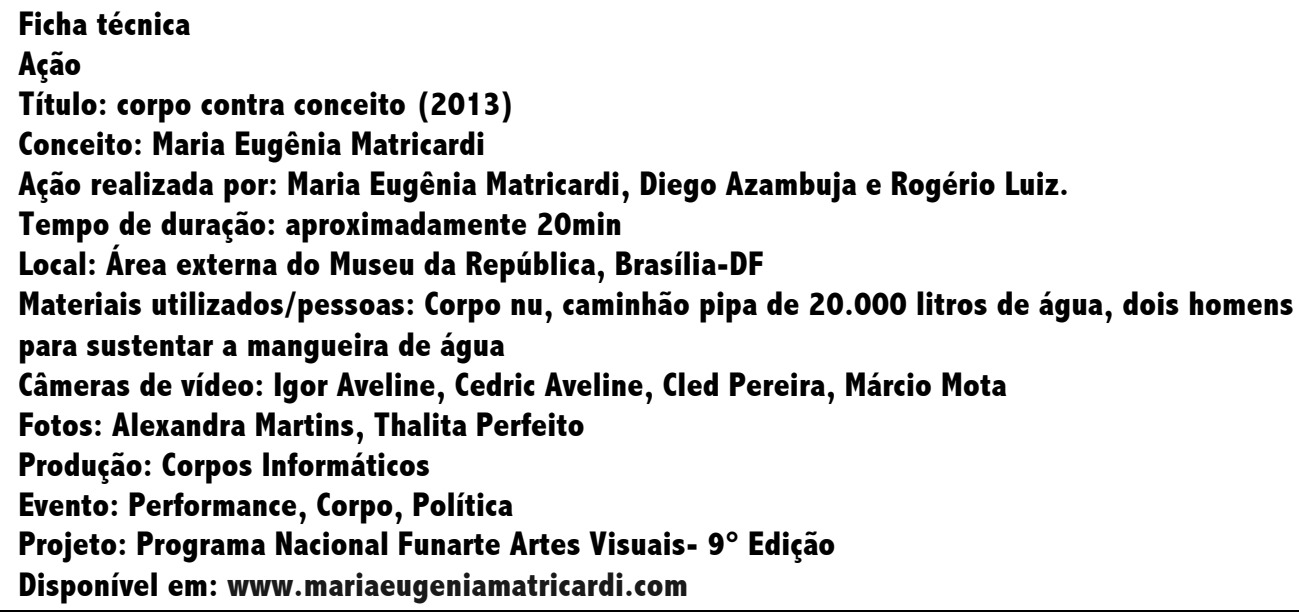

\section{corpo contra conceito ${ }^{1}$}

Maria Eugênia Matricardi

Este artigo apresenta, em formato adaptado, o segundo capítulo da dissertação de mestrado de título "Ações, políticas estéticas, heterotopias nômades : lugares possíveis" de Maria Eugênia Lima Soares Trondoli Matricardi, defendido em abril/2016 pelo Programa de Pós-Graduação em Arte do Departamento de Artes Visuais da Universidade de Brasília, na linha de pesquisa em Poéticas Contemporâneas, sob orientação da profa. Dra. Maria Beatriz de Medeiros com banca composta por Miguel Gally e Luisa Günther. Disponível em: http://repositorio.unb.br/handle/10482/21548 
METAgraphias: letra D de dropbox (das derivas dançantes) v.2 n.1 marçol2017 corpo contra conceito • Maria Eugênia Matricardi (m.eugeniamatricardi@gmail.com(

Uma borboleta branca sobrevoa o vapor úmido, próxima à cachoeira. Uma gota assertiva pode lhe aniquilar a vida, destruir suas asas de seda frágeis.

Ela se arrisca por encantamento.

Como se arriscaram por encantamento da luz da lâmpada os insetos carbonizados.

Assim fui acometida por uma imagem: meu corpo nu recebendo um fluxo de água intenso da mangueira de um caminhão. Uma nitidez que não passa pelas palavras, pois as palavras nos enveredam pelo labirinto da dúvida. Lucidez delirante assumindo os desejos com a crueldade que eles desejam sentir. Não há submissão, há entrega. O que somos capazes de fazer por uma sensação? Não se sabe. Acredito que muito. Era algo mais próximo à intuição, ao não-sabido, imagem praticamente intacta, sensação que permaneceu consistente até ser executada. Não havia muito que dizer. Caberia apenas ser na sensação, assumir a imagem como experiência e confiar na força que ela invocava. Mergulhar na sensação até deixar de tê-la, ou ainda, ser-sensação e na sensação como um estado que percorre corpointeiro [sic]. e abandona o organismo. "Sem boca. Sem língua. Sem dentes. Sem laringe. Sem esôfago. Sem ventre. Sem ânus. Toda uma vida não orgânica, pois o organismo não é a vida, ele a aprisiona. O corpo é inteiramente vivo, no entanto não orgânico", (DELEUZE, 2007, p.52).

Um corpo nu, um caminhão pipa com vinte mil litros de água, dois homens para segurar a mangueira, uma estrutura arquitetônica limpa visualmente, fim de tarde, pôr-do-sol. Água, luz, corpo. Água densa, flexível, abraça formas existentes, se molda, flui capaz de deformar e perfurar as superfícies mais duras. Onda rebentando pedra. Nascem outras formas. Retiro o roupão, me posiciono nua de costas para a parede externa do museu, peço para acionarem a mangueira na pressão máxima. O corpo intima o fluxo, estabelece lugar de combate. O jorro de água comprime, deforma a carne, superfície contra superfície; espaço incidente onde as coisas se manifestam em sua materialidade somente em relação ao seu limite contra o espaço. Contraposição: estar contra como forma de engendrar com-tato, zonas de aderência. 


\section{Corpo contra conceito.}

\section{Conceito contra conceito.}

Corpo contra corpo.

Na vulnerabilidade de deixar-se escorrer, deixar o corpo vibrar sem organismo. Pele água, pele fluxo, pele ar, quase nada, poça no chão. O corpo incorre, escorre, se lança, se expõe, flui, se deixa arrebatar pela pressão do jato, é empurrado contra o duro, concreto, realidade: limite inegável que se impõe como barreira material. Se é na "realidade de um virtual" que o conceito traz que se desdobram extensões na dimensão material, é no material, na realidade que este atua. Ele atua no limite material propondo deslimites. Ainda que haja capacidade de evaporação, ebulição e condensação como a água, trazendo-nos tempestades variáveis (SERRES, 2001), chuvas calmas, rastro de orvalho.

A violência desta ação nada tem a ver com a violência das guerras ou da polícia. Em ambos os casos a violência transpassa o corpo, o sistema nervoso, a carne. Mas uma lhe faz mergulhar na sensação abrindo caminhos para que se possa conhecer outros lugares de experimentação, onde a vida não depende do organismo, por isso mesmo vai além dos limites do que é representado, vivido. A outra lhe rouba a subjetividade, atua por medo e constrangimento, determina e localiza os lugares onde podem habitar as sensações, estancando, desta forma, a potência do sensível. Se me lanço na tempestade variável é para sentir o corpo vibrar, não o organismo.

O jato de água violento dispersa manifestações, cala a revolta dos presos em ritual humilhatório, controla. Ele é trazido na ação com a crueza arrebatadora de um poder, sem o horror destas imagens, somente com a sensação que o torna controle presente em diversos níveis, agência do poder imanente sobre o corpo, deformando a carne. Este é um fato recorrente, mas se atualiza na ação como acontecimento singular. Preferi usar poucos elementos, deixar acontecer com força de reverberação própria, sem poluição visual ou simbólica. A brutalidade não anula a beleza, elas se acoplam em intencionalidade não objetiva. 
A ação foi prevista para as 17 horas, tendo tido, portanto, forte apelo visual devido à arquitetura de concreto crua, um trecho da Esplanada cimentada um jato d'éaua e as cores de um pôr- do- sol brasiliense refletido sobre a água em superfície lisa. Chão de espelho, real, virtual, céu, arquitetura, pessoas, corpo diluído.

\section{Blocos de sensações, afectos e perceptos}

Conforme Gilles Deleuze e Félix Guattari (2010), a arte busca extrair blocos de sensações, ela é em si o lugar das sensações que penetra na matéria dos corpos e objetos em arte e na materialidade das palavras. A arte capta a energia vibrátil das coisas e faz com que o possível surja como categoria estética que re-existe no vivido. Buscamos possíveis para não sufocar, não buscamos verdade. Os blocos de sensações são formados por um composto de sensações, perceptos e afectos. A única regra que permeia este bloco é o fato deste manter-se em pé por si só. Às vezes esse bloco usa muletas institucionais, fica sentado na cadeira do prestígio, anda mal das pernas. Ainda assim permanece, se constitui como bloco.

As ações captam a vibração das coisas, se deixam vulneráveis, já não muito preocupadas com a consistência evocada por tais blocos. Os blocos de sensações formam um conceito interessante, no entanto, a imagem que esse conceito traz parece dura, fixa. Quem produz arte trabalha para que se faça erigir blocos de sensações, mas não há esforço sem que se crie um ser de sensação com consistência e autonomia própria. Sem autonomia, os seres de sensação não sobrevivem. A impetuosidade gerada advém da própria qualidade do composto. Os perceptos diferem das percepções, porque eles atuam como um conjunto de percepções e sensações que independem daqueles que os experimentam. Os perceptos sobrevivem para além daqueles seres que os sentem. 
Algo consiste, permanece, por mais efêmero que tenha sido o momento da experimentação, como na ação, que mantém sua relação com o tempo pela própria capacidade de degenerar-se como gesto, mantendo uma qualidade de consistência nas forças captadas, afecto e percepto para além da materialidade do tempo.

Depois de extinguir-se no tempo a ação consiste, se puder, ou apenas se perde. Me pergunto se ela perdura como duração, uma eternidade que habita o entre-tempo. A ação se extingue para manter-se, sua gênese está no sacrifício. $O$ registro é atualização do devir da ação no presente, não é somente memória, nem o gesto em si. Registro, diferente da ação em si já é algo desterritorializado de tempo. É no tempo que aconteço, que o nó do corpo se dá com o espaço, com quem iterage, com as coisas nas quais me transformo, com o gosto, o cheiro, o sol ardido na cara, sem deixar de ser,

sem deixar de me outrar.

O que se conserva, de direito, não é o material, que constitui somente a condição (enquanto a tela, a cor ou a pedra virem pó), o que se conserva em si é o percepto e o afecto. Mesmo se o material durasse apenas alguns segundos, daria à sensação o poder de existir e de se conservar em si, na eternidade que coexiste com a curta duração. (DELEUZE \& GUATTARI, 2010, p.197)

Sendo a ação algo que não se diferencia da vida, gesto estetizado sim, intencional, poético, no entanto, grávido de inusitado, de vibratilidade do corpo, das coisas que passam, portanto, vulnerável, me pergunto: o que se preserva? Até que ponto o afecto se preserva para além do registro? Se a cada vez o registro é reatualizado pelo corpo que o presencia, os afectos também mudam, criam diferença. Se o registro for descontextualizado, os afectos serão completamente diferentes. Devir registro. Parece-me haver vontade de permanência. Talvez isso se aproxime mais da "obra" de arte que aspira ao eterno escrita na superfície do mundo. A ação em si, mesmo com presença de registro, flerta com o esquecimento, a decomposição que se esfarela entre dedos. A eternidade não me chega. Interessa a vida, a imanência, o que morre: gesto que esvai. 
afecto como um devir, pode ser encontro não humano no humano, nossa capacidade de contrair as coisas tornando-nos elas. Não é a passagem de um estado vivido a outro, mas uma contiguidade extrema entre uma sensação e outra; devir-humano, devir-água, devir-carnal e mineral sem que haja diferenciação, uma zona de indiscernibilidade. A água arrebenta a dor que há na pele. Pele-água escorrendo. O fluxo-jato lava a lucidez do corpo. Derretimento. Densidade. Água- viva. Absorção. Não absorvo nada, as coisas me absorvem. "Há um minuto do mundo que passa, não o conservaremos sem „nos transformarmos nele", diz Cézanne. Não estamos no mundo, tornamo-nos com o mundo, nós nos tornamos contemplando-o.” (DELEUZE \& GUATTARI, 2010, p.200).

Para mim, os afectos são os devires. São devires que transbordam daquele que passa por eles, que excedem as forças daquele que passa por eles. O afecto é isso. Será que a música não seria a grande criadora de afectos? Será que ela não nos arrasta para potências acima de nossa compreensão? É possível. (DELEUZE, 1996)

O que se pode dizer quando o corpo abandona o organismo e surgem as sensações, perceptos e afectos que excedem qualquer vivido? Não seria esta uma possibilidade de criar afectos, lugares de sensação que indeterminam nossa compreensão? Não seria uma característica da ação diluir a diferenciação entre arte e vida? Preferir-se ação, como vida ao invés de performance? Ação cria em si diferença, um desvio itálico em sua grafia, sem distanciar-se do cotidiano em sua sonoridade. Ação, apenas, como gesto intencional no mundo sem metodologia. Se você quer metodologia há que prever todos os gestos possíveis. Que instituição se arrisca a tal feito? Talvez, seja nesta força "criadora de afectos" que "nos arrasta para potências acima de nossa compreensão" que a vida se manifesta para além de todo o vivido. O que seria para além do vivido, se nele experimentamos os lugares possíveis? Não é fora do corpo, do mundo, da imanência. Talvez, fora do organismo. Só o corpo, não o organismo, pode suportar a exuberância da vida. "A carne é somente o revelador que desaparece no que ela revela: o composto de sensações.” (DELEUZE \& GUATTARI, 2010, p.216). 
Se a ação se baseia no vivido, no cotidiano, se ela transita por opiniões, não é para buscar o espetáculo. Ela abre via para tornar sensíveis forças insensíveis do cotidiano. É por força de banalidade que o ato de lavar as mãos, por exemplo, pode ser injetado de estesia, reconfigurando regimes estéticos (RANCIÈRE, 2009) que indiferenciam a imanência do vivido e a arte.

O gesto no vivido sem o mínimo de desterritorialização, diferença, estesia, não costuma ter consistência nem saturação: escovar os dentes é só isso mesmo. Escovar os dentes no saguão do aeroporto, trazendo um gesto íntimo de higiene pessoal para um lugar público, cria diferença. Em algumas ações o gesto é injetado de vida, re-existindo de outra forma, fazendo o corpo vibrar outras frequências.

Nas ações, o corpo se torna vulnerável, deixando-se atravessar por perceptos e afectos. Seria difícil, no entanto, dizer encarnar perceptos e afectos, pois o afecto seria o devir-outro, e é o afecto que constitui a sensação, não a carne, a carne é via de..., mas ela revela quando desaparece, quando é abandonada. É no próprio corpo que este bloco de sensações, cria um ser de sensação que atravessa a carne e encontra a realidade do devir.

[...] é a carne que vai se libertar ao mesmo tempo do corpo vivido, do mundo percebido, e da intencionalidade de um ao outro, ainda muito ligada à experiência, enquanto a carne nos dá o ser da sensação, e carrega a opinião originária, distinta do juízo de experiência. Carne do mundo e carne do corpo, como correlatos que se trocam, coincidência ideal. (DELEUZE \& GUATTARI, 2010, p. 210-211).

Não penso em representação do conceito como fluxo de água, mas a tentativa de captar, extrair a sensação do conceito por via da força de afecto que a água possui. $\bigcirc$ afecto, que é o próprio devir, deforma o corpo em água. Não que o corpo tenha se transformado em água, mas havia ali uma zona de indiscernibilidade que percorreu o corpo: não havia possibilidade de suportar a força da água sem que eu me tornasse água, ser em sensação de água. 
Captação de forças de deformação, exaustão, diluição, fluidez e resistência. Não há limites, mas limiares, níveis de força, de vulnerabilidade, que produzem saltos de estados de corpo.

\section{Corpo sem Órgãos (CsO)}

Para captar uma determinada força de sensação é necessário deixar-se permear por ela, torná-la visível. É necessário ser frágil para abrir-lhe caminhos e ser forte para suportá-la, porque nem sempre a melhor sensação para uma ação é a mais agradável. Com muita frequência não é. Olhar o corpo e enxergar a presença. Isso é estar em um lugar ilocalizável. E presença não se explica tampouco se vê com olhos de quem vê apenas o visível. Não há olho fixo, há talvez um olho para cada poro, percorrendo como átomos pelo vazio do qual as formas são preenchidas.

Não é uma noção, um conceito, mas antes uma prática, um conjunto de práticas. Ao Corpo sem Órgãos não se chega, não se pode chegar, nunca se acaba de chegar a ele, é um limite. Diz-se: que é isto-o CsO-mas já se está sobre ele-arrastando-se como um verme, tateando como um cego ou correndo como um louco, viajante do deserto e nômade da estepe. (DELEUZE \& GUATTARI, 1996, p.9-10).

Afastar de si o que é fácil. Nessa ação há esforço, há fraqueza, há mergulho nas próprias sombras para encontrar leveza. O corpo tem sabedoria própria, sabe pelo sabor, experimenta com corpointeiro algo isolado no abissal de suas sensações que se escapa de si. Este possui caminhos que não deixam rastros, ativa seus próprios agentes despovoadores. Despovoar-se se dá por via de algo, não pode ser nomeado, e os conceitos, por mais que promovam movimentos infinitos e sobrevoos por todos os planos de imanência do pensamento, tanto na arte (planos de composição), quanto na filosofia (planos de imanência), ou na ciência (planos de referência), tem por característica d(en)ominar, dominar em algo. 
O conceito pode criar conceitos de sensações, acoplar-se a outros planos de imanência, ou planos de composição, mas não é por via do conceito que o corpo abandona o organismo e mergulha na força que as sensações capturam para atingir uma qualidade de pensamento não-pensante, capaz de contrair as coisas por contemplação, ser-outro em puro afecto. $O$ conceito não experimenta o Corpo sem Órgãos.

Interessa às ações a imagem que atravessa, deixando margens para que se construam muitos sentidos, para que o conceito seja catapulta para lançar o pensamento a territórios não frequentados. O conceito se constitui de variações inseparáveis. Eles multiplicam-se como fractais, levando o pensamento a lugares desconhecidos. Uma variação que leva à outra, que leva à outra e outra em movimento de velocidade infinita. Mas estas variações estão conectadas, dialogam umas com as outras em congruência de finalidade, não subsistem como um fim em si mesmo. São estas variações que "amarram" o conceito. "Um conceito é um conjunto de variações inseparáveis, que se produz ou se constrói sobre um plano de imanência, na medida em que se recorta a variabilidade caótica e lhe dá consistência (realidade)." (DELEUZE \& GUATTARI, 2010, p.255).

Interessa às ações as sensações que estesiam o corpo, que pensam sem entendimento e sabem pelo sabor. Elas se acoplam, formam coagulações, não exigem coerência pois são

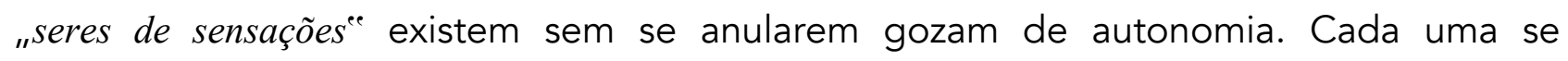
comporta como um fim em si mesmo, nem qualificantes, nem qualificáveis.

A planta contempla contraindo os elementos dos quais procede, a luz, o carbono e os sais, e se preenche a si mesma com cores e odores que qualificam sempre sua variedade, sua composição: é sensação em si. Como se as flores sentissem a si mesmas sentindo o que as compõe, tentativas de visão ou de olfato primeiros, antes de serem percebidas ou mesmo sentidas por um agente nervoso e cerebrado. (DELEUZE, GUATTARI, 2010, p. 250).

Interessa ao corpo, às ações, o saber que não passa pelo entendimento, nem pelo conceito. Que não se d(en)omina. O impacto dos vinte mil litros de água já não afogava mais. Não me defendia. Me entregava. 
A dor que mobilizava a pele e todos os órgãos foi dissipada em força exaustiva. O corpo se entregou ao chão, sem esforço, sem força. Alguém me levantou, conduziu minha carne até o banheiro do museu. Me olhei no espelho, não reconheci o reflexo. Vi apenas uma carcaça refletida. O corpo abandonou o organismo revelado pela carne que escorreu junto às ultimas gotas que caíram da mangueira do caminhão-pipa. Não me reconheci, já não estava lá. Havia uma forma refletida no espelho que não era a minha. "Portanto, quando a sensação atinge o corpo através do organismo, adquire um caráter excessivo e espasmódico, rompe os limites da atividade orgânica. Em plena carne, ela age diretamente sobre a onda nervosa ou a emoção vital." (DELEUZE, 2007, p.52).

O vazio. As sensações se compõem com o vazio? Ou seria o vazio ser de sensação? Vazio que aciona agente despovoador. Retornei à forma ulterior de ovo, sem vetores, nem direções, nem ossos, nem estratos, onde a forma não importa e o saber não tem mais fôlego. Um mergulho no ovo, lugar possível de onde nasce a vida inorgânica, rompendo a frágil casca do organismo. Deslimites do vago.

\section{Referências Bibliográficas}

DELEUZE, Gilles. L'ABÉCÉDAIRE de Gilles Deleuze. Entrevista concedida a Claire Parnet, 1988. 1a transmissão programa Metropolis, canal ARTE, 1996.

DELEUZE, Gilles. Francis Bacon. Lógica da sensação. Rio de Janeiro: Jorge Zahar Editor, 2007.

DELEUZE, Gilles e GUATTARI, Félix. O que é filosofia? Rio de Janeiro: Editora 34, 2010. 